\title{
Understanding Human Microbiota Offers Novel and Promising Therapeutic Options against Candida Infections
}

\author{
Saif Hameed ${ }^{1}$, Sandeep Hans ${ }^{1}$, Ross Monasky ${ }^{2}$, Shankar Thangamani ${ }^{2, *}$ and Zeeshan Fatima ${ }^{1, *}$ \\ 1 Amity Institute of Biotechnology, Amity University Haryana, Gurugram, Manesar 122413, India; \\ saifhameed@yahoo.co.in (S.H.); sandeephans12@gmail.com (S.H.) \\ 2 Department of Pathology and Population Medicine, College of Veterinary Medicine, Midwestern University, \\ Glendale, AZ 85308, USA; rmonas@midwestern.edu \\ * Correspondence: sthang@midwestern.edu (S.T.); drzeeshanfatima@gmail.com (Z.F.)
}

Citation: Hameed, S.; Hans, S.

Monasky, R.; Thangamani, S.; Fatima,

Z. Understanding Human Microbiota Offers Novel and Promising

Therapeutic Options against Candida Infections. Pathogens 2021, 10, 183.

https://doi.org/10.3390/

pathogens10020183

Academic Editor: Ying-Lien Chen

Received: 4 October 2020

Accepted: 2 February 2021

Published: 9 February 2021

Publisher's Note: MDPI stays neutral with regard to jurisdictional claims in published maps and institutional affiliations.

Copyright: (c) 2021 by the authors. Licensee MDPI, Basel, Switzerland. This article is an open access article distributed under the terms and conditions of the Creative Commons Attribution (CC BY) license (https:// creativecommons.org/licenses/by/ $4.0 /)$
Abstract: Human fungal pathogens particularly of Candida species are one of the major causes of hospital acquired infections in immunocompromised patients. The limited arsenal of antifungal drugs to treat Candida infections with concomitant evolution of multidrug resistant strains further complicates the management of these infections. Therefore, deployment of novel strategies to surmount the Candida infections requires immediate attention. The human body is a dynamic ecosystem having microbiota usually involving symbionts that benefit from the host, but in turn may act as commensal organisms or affect positively (mutualism) or negatively (pathogenic) the physiology and nourishment of the host. The composition of human microbiota has garnered a lot of recent attention, and despite the common occurrence of Candida spp. within the microbiota, there is still an incomplete picture of relationships between Candida spp. and other microorganism, as well as how such associations are governed. These relationships could be important to have a more holistic understanding of the human microbiota and its connection to Candida infections. Understanding the mechanisms behind commensalism and pathogenesis is vital for the development of efficient therapeutic strategies for these Candida infections. The concept of host-microbiota crosstalk plays critical roles in human health and microbiota dysbiosis and is responsible for various pathologies. Through this review, we attempted to analyze the types of human microbiota and provide an update on the current understanding in the context of health and Candida infections. The information in this article will help as a resource for development of targeted microbial therapies such as pre-/pro-biotics and microbiota transplant that has gained advantage in recent times over antibiotics and established as novel therapeutic strategy.

Keywords: Candida; microbiota; oral; nasopharyngeal; gut; gastrointestinal; vaginal; metabolite

\section{Introduction}

Invasive fungal infections may be life-threatening due to occurrence of diabetes and immuno-compromization caused by AIDS, cancer, organ transplants, corticosteroids, postsurgical care, broad-spectrum antibiotic use, etc. [1]. Localized fungal infections that are usually apparent can become systemic, causing deep seated infections as the disease occurrence persists. Despite significant improvements in antifungal drug development, there are still a limited number of available antifungal drugs that are effective. Among infections caused by these opportunistic fungal pathogens, Candida species are responsible for the most threatening, invasive mycotic infection and candidiasis. Candida albicans is responsible for over half the cases of candidiasis in humans. Over the past two decades, many non-Candida albicans Candida (NCAC) species have also emerged as significant pathogens of clinical importance [2,3]. These species are a highly diverse group of organisms and are fundamentally different from each other, including C. albicans, at the biological level [4]. This diversity in the range of Candida species now associated with human infections has provided new challenges in the diagnosis and treatment of candidiasis and in the study of 
their virulence and biology. Additionally, species previously considered as nonpathogenic, C. glabrata, C. krusei, and C. lusitaniae have also emerged as pathogens $[5,6]$. A number of NCAC species are now recognized to exhibit intrinsic resistance to antifungals. Because of their evolutionary similarity to their human hosts, fungal pathogens create additional therapeutic challenges when designing interventions. This similarity restricts the potential drug targets available to selectively kill the pathogen without affecting the host [7]. As a result, there is urgency for deployment of novel approaches to surmount the Candida infections.

The pathogenesis of Candida spp. is governed by several factors that include yeast to hyphal and phenotypic switching, biofilm formation, adherence and invasion, metabolic flexibility, genome plasticity, $\mathrm{pH}$ stress and limiting micronutrients, escape from phagocytosis, host immune evasion, resistance to antifungal agents, and interaction with resident microbiota [8]. The human microbiota is microbial communities that reside inside or on the external surface of the human body, and their genetic makeup is known as the human microbiome [9]. Each microbiota has a unique, synergistic relationship of microbes with the host that acts as the first line of defense against the invading opportunistic pathogens. This mutually beneficial state is known as eubiosis, contrary to disrupted symbiotic balance, occurring by outweighing of opportunistic pathogens, referred to as dysbiosis. Thus, other microorganisms residing in the human body play a major role in human health and diseases progression. Little is known about how microbes interact with each other and influence the host immune system. Understanding the microbiota thus represents a critical aspect in gaining insight into disease progression and prevention. Herein, we reviewed the recent information of the various microbiota present in humans and their influence on the opportunistic Candida spp. This will help establishing a resource with information for identifying distinct microbiota profiles associated with Candida infections.

\section{Types of Microbiota}

\subsection{Oral Microbiota}

The oral cavity is the first digestive organ that metabolizes starches and dietary lipids, two significant vitality sources for physiology and microbial development. The oral microbiota is a unique and significant part of the human microbiota, and comprises the microorganisms existing in the human oral cavity. The oral cavity is understood to have the second most complex microbiota inside the human body, comprising extremely diverse organisms from all domains of life. Among nearly 700 species found in the oral cavity, about $54 \%$ have been cultivated and named, $14 \%$ are cultivated but unnamed, and $32 \%$ are recognized simply as unrefined phylotypes (from the Human Oral Microbiome Database) [10].

\subsubsection{Microbial Niches of Oral Cavity}

The oral microbiota plays a significant role in maintenance of mouth homeostasis. Every person's oral microbiota comprises a diverse and varied group of microbes. Due to its position, microbial growth in the oral cavity is affected by several variables including: personal hygiene, nutrition, and smoking in some cases along with host driven genetic factors that may have additional effects on the oral microbes [11]. The humid surroundings of the oral cavity are maintained at a relatively consistent temperature $\left(34-36^{\circ} \mathrm{C}\right)$, although the fluctuating $\mathrm{pH}$ levels, and the factors listed above also impact the microbiome variability.

In the oral microbiota, bacteria are the main oral microorganisms. The oral bacterial community is comprised primarily of these six major phyla, Firmicutes, Bacteroidetes, Proteobacteria, Actinobacteria, Spirochaetes and Fusobacteria, with around $94 \%$ of the taxa detected [12-14] (Table 1). The other phyla, Saccharibacteria, Synergistetes, Gracilibacteria, Chlamydia, Chloroflexi, Tenericutes, and Chlorobi, comprise the remaining $6 \%$ of the taxa. The human microbiota diversity is not restricted to bacteria but also extends to fungi as well. Fungi are found in the oral microbiota as both opportunistic pathogens and as members of healthy oral microbiota. Many studies reported that 101 fungal species are existent in healthy people in which Candida species are the most common, followed by 
Cladosporium, Aureobasidium, Saccharomyces, Aspergillus, Fusarium, and Cryptococcus [15]. The most frequent fungal species is C. albicans followed by Candida parapsilosis, Candida tropicalis, Candida khmerensis, and Candida metapsilosis [16]. Archaea consist as a minor part and only a few species are found in the oral microbiota like Thermoplasmatales, Methanobrevibacter, Methanobacterium, Methanosarcina, and Methanosphaera [17,18]. Of note, some viruses found in the mouth such as Herpes virus cause significant disease of the mouth and mucocutaneous surfaces and can cause recurrent, chronic lesions on the face and lips [19].

Table 1. Diverse microbiota depicting resident phyla along with those associated with Candida infections.

\begin{tabular}{|c|c|c|c|}
\hline Types of Microbiota & Resident Phyla & Phyla Influencing Candida Infections & Reference \\
\hline Oral & $\begin{array}{c}\text { Firmicutes, Bacteroidetes, Proteobacteria, } \\
\text { Actinobacteria, Spirochaetes, Fusobacteria, } \\
\text { Saccharibacteria, Synergistetes, } \\
\text { Gracilibacteria, Chlamydia, Chloroflexi, } \\
\text { Tenericutes and Chlorobi, Ascomycota, and } \\
\text { Basidiomycota }\end{array}$ & $\begin{array}{c}\text { Firmicutes (Streptococcus, Lactobacillus), } \\
\text { Bacteroidetes (Porphyromonas), } \\
\text { Proteobacteria (Aggregatibacter), } \\
\text { Actinobacteria (Actinomyces), }\end{array}$ & [12-15] \\
\hline Nasopharynx & $\begin{array}{c}\text { Proteobacteria, Firmicutes, Bacteroidetes, } \\
\text { Actinobacteria and Fusobacteria, } \\
\text { Ascomycota, }\end{array}$ & Proteobacteria (Pseudomonas) & {$[20,21]$} \\
\hline Gut & $\begin{array}{c}\text { Bacteroidetes, Firmicutes, Actinobacteria, } \\
\text { Proteobacteria, Ascomycota, and } \\
\text { Basidiomycota }\end{array}$ & $\begin{array}{c}\text { Firmicutes (Streptococcus, Lactobacillus), } \\
\text { Bacteroidetes (Bacteroides), } \\
\text { Proteobacteria (Esherichia, Salmonella) }\end{array}$ & [22-25] \\
\hline Gastrointestinal & $\begin{array}{c}\text { Bacteroidetes, Firmicutes Ascomycota, } \\
\text { Basidiomycota Chytridiomycota and } \\
\text { Euryarchaeota }\end{array}$ & $\begin{array}{l}\text { Firmicutes (Streptococcus, Lactobacillus), } \\
\text { Proteobacteria (Esherichia, Helicobacter) }\end{array}$ & {$[26,27]$} \\
\hline Vaginal & $\begin{array}{c}\text { Firmicutes, Bacteroidetes, Proteobacteria, } \\
\text { Actinobacteria, Tenericutes, Ascomycota, } \\
\text { Basidiomycota, and Oomycota. }\end{array}$ & $\begin{array}{c}\text { Firmicutes (Lactobacillus, Streptococcus), } \\
\text { Proteobacteria (Esherichia) }\end{array}$ & [28-30] \\
\hline
\end{tabular}

\subsubsection{Candida and Bacteria Interaction in Oral Cavity}

C. albicans is the fungus commonly found in the oral cavity through any dysbiotic illness, while the predominant bacterial species is $S$. mutans. The proximity of these microbes in youth caries and dental plaques [31] indicates that these organisms may have interactions which impact the sickness. Some in vitro studies reported C. albicans initiated articulation of the $S$. mutans destructiveness quality of glucosyltransferase B (GtfB) [14]. Remarkably, GtfB can likewise adhere to the outside of C. albicans, promoting adherence to dental surfaces and prompting the development of blended biofilms [32]. RNA-Seq analysis performed on co-cultures revealed that the closeness of C. albicans impacts carbohydrate digestion pathways in S. mutans [33]. Additionally, the accumulation of Lactobacillus salivarius with many species forms biofilms but can obstruct development of $S$. mutans and C. albicans biofilms in vitro [34]. Metabolic investigations of both species consequently found intermediate increases in abundance of formate and farnesol. The most abundant molecule detected, farnesol, improves $S$. mutans cell development and micro colony growth in biofilms comprised of both C. albicans and S. mutans [35]. Further studies convey proof for $S$. mutans reducing the pathogenicity of $C$. albicans. Infusion of $S$. mutans cells consumed by C. albicans-infected Galleria mellonella larvae enhances endurance of the creatures [36]. Furthermore, AgI/II family polypeptides in S. mutans have connections with C. albicans and help establishment of two microorganisms in a D. melanogaster in vivo model [37].

The streptococci mitis group has been well-known to interact with $C$. albicans. The mitis group are typical oral commensal bacteria, which includes 13 types of streptococci with four species, namely, S. gordonii, S. mitis, S. oralis, and S. sanguinis, prevailing in their capacity to communicate directly with C. albicans [38]. Additionally, a previous murine model study showed better establishment of $S$. oralis in the oral microbiota in the 
occurrence of $C$. albicans. Moreover, co-infection supported profound organ propagation of C. albicans [39]. In addition, discharge of $S$. gordonii QS molecule autoinducer-2 (AI-2) induces higher hyphae expansion through co-incubations [40]. In a murine co-infection model, there were enhanced levels of proteolytic host protein $\mu$-calpain targeting E-cadherin leading to activation of systemic invasion of C. albicans. S. sanguinis showed synergistic effects with C. albicans through biofilm formation [41]. S. sanguinis produces a bacteriocin which showed antibacterial activity against $P$. gingivalis and $P$. intermedia and affected filamentation of Candida spp. [42].

Besides streptococci, numerous other oral microorganisms also interact with C. albicans. For instance, the periodontal pathogens Aggregatibacter actinomycetemcomitans and Fusobacterium nucleatum impede propagation of C. albicans by elimination of quorum sensing molecule AI-2 [43]. Co-cultivation of $C$. albicans and anaerobic Porphyromonas gingivalis in standard oxygen conditions enhances growth of $P$. gingivalis in the presence of $C$. albicans biofilm, which suggests protection of P. gingivalis under aerobic conditions [44]. Moreover, an in vitro experiment validates $P$. gingivalis being able to interrupt oral epithelium cell movement while interrelating with another Candida spp. such as C. kefyr and C. glabrata [45]. A study displayed that Actinomyces species like A. viscosus, A. naeslundii, and A. odontolyticus could constrain the growth of $C$. albicans. C. albicans adherence to oral epithelial cells was reduced and production of phospholipase $C$ was improved in the presence of supernatants from Actinomyces spp. [29]. Rothia dentocariosa is developing as an opportunistic bacterium and usually is collected with C. albicans from failed silicone voice prostheses in subjects who endured laryngectomy [46]. S. aureus is also normally found in healthy oral microbiota, [47] along with oral diseases which generally are related to the incidence of C. albicans, like denture stomatitis [48] and angular cheilitis [49].

\subsubsection{Oral Dysbiosis}

C. albicans colonization in mucosal sites is restricted by commensal bacterial communities. However, under immunosuppressed conditions when the microbial homeostasis is changed certain bacterial species form mutualistic connections with C. albicans [50,51]. Immunocompromised conditions led to dysbiosis leading to mucosal damage. A change towards dysbiosis is usually led by dietary changes or antibiotics reducing diversity. Changes in the homeostatic balance lead to bacteria-mediated diseases such as dental caries, endodontic infections, gingivitis, and periodontitis [52,53]. Oral candidiasis leads to damage to the oral mucosal surface and is caused when the superficial tissue layers are colonized, overgrown, and invaded by Candida species. One cause of oral Candida overgrowth is dysbiosis due to immunosuppression, for instance, HIV infection [54].

\subsection{Nasopharyngeal Microbiota}

The nose and nasopharynx are vital niches colonized by commensal and potential pathogenic species which together comprise the nasopharyngeal microbiota. In humans and mammals, the nasal cavity is well identified as an essential site for colonization by diverse bacterial and fungal species. The nasopharynx is the dominant microbiota present in other regions of the upper respiratory tract, and the nasopharyngeal (NP) microbiota arises from early colonization. In humans, although Candida spp. are not considered as significant constituents of the upper respiratory tract microbiota, their existence may be relevant to immune responses in this region.

\subsubsection{Microbial Niches of Nasopharyngeal Microbiota}

NP microbiota profiles are not stable during early development, and the microbiota transforms as development occurs. For example, in infants, NP microbiota are characterized by majorly the phyla Proteobacteria, Firmicutes, Bacteroidetes, Actinobacteria, and Fusobacteria, with the most prominent genera being Moraxella, Haemophilus, Streptococcus, Dolosigranulum, Corynebacterium, and Neisseria [55] (Table 1). In the case of detected genera in adults, while Staphylococcus, Haemophilus, and Streptococcus are extant, also present 
are Sphingobacterium, Prevotella, Bifidobacterium, Rothia, and Propionibacterium, but neither Moraxella nor Corynebacterium [20]. In the case of fungi, among the 25 species of yeasts in the NP microbiota that are considered as emerging pathogens, 20 are Candida spp. [21].

\subsubsection{Candida and Bacteria Interaction in Nasopharyngeal Microbiota}

The NP microbiota has substantial microbial interactions in the form of synergism and antagonism. During S. aureus colonization, H. influenzae and M. catarrhalis display a strong negative impact on $S$. aureus colonization compared to $S$. pneumoniae [56]. Strong positive relations in colonization amongst S. pneumoniae, $M$. catarrhalis, and H. influenzae have also been documented $[57,58]$. The synergistic association is that colonization of $S$. pneumoniae and $H$. influenzae rises during co-culture [59]. M. catarrhalis shows a strong interaction with $H$. influenzae, by avoiding complement-mediated killing through accompaniment inhibition of C3. A study revealed that commensal microbes understood to have little pathogenic potential also communicate in this environment [60]. For instance, Corynebacterium and Dolosigranulum were earlier believed to be factors in reducing $S$. aureus abundance [61]; however, not all Corynebacterium spp. were shown to inhibit S. aureus [62]. Pneumococcus has displayed greater biofilm density when forming multi-species biofilms with $H$. influenza. Regarding the role of fungi in the NP microbiota, it includes some specific species that help in interaction with other species of bacteria and fungi. Aspergillus, Candida, and Cryptococcus are found in respiratory samples from persons with multiple risk factors such as immunodeficiencies [63], and it has been established that fungal colonization can be related with asthma and chronic respiratory disease [64]. Furthermore, in a rat model, C. albicans damages macrophage-mediated clearance of Pseudomonas aeruginosa during pneumonia [65], and in biofilm models, it also influences infection and mucosal inflammatory response towards Streptococcal disease [66].

\subsubsection{Nasopharyngeal Dysbiosis}

NP dysbiosis alters the commensal microbiota, disrupting homeostasis, and this dysbiosis influences mucosal and systemic immunity by creating inflammatory responses within the host [67]. Direct colonization of the upper respiratory tract in elderly populations is low for pathogens such as Streptococcus pneumonia, a major cause of pneumonia and more invasive disease [68]. Additionally, murine models show the composition of the NP microbiota changes during $S$. pneumoniae colonization in which the elderly mice were not able to clear S. pneumoniae as successfully as the young mice [69]. However, other studies suggest that the NP microbiota is the important factor in this colonization, as the most assorted adult microbiotas are also the lowest expected to find S. pneumoniae [70]. The NP commensal Haemophilus influenzae is among six capsulated varieties and was a major contributor in life-threatening infections like meningitis and septicemia. Moreover, non-typable Haemophilus influenza (NTHi) is also responsible for acute, mucosal or chronic infection. Additionally, the impact of M. catarrhalis can be seen prominently in acute mucosal infections and in chronic obstructive pulmonary disease (COPD) [71]. Additional severe diseases are also recognized as a consequence of dysbiosis and comprise bacteremia, sepsis, mastoiditis, septic arthritis, and endocarditis [72-74].

\subsection{Gut and Gastrointestinal Microbiota}

The human gut and the gastrointestinal microbiota are a composite, populated by diverse species of bacteria, fungi, and archaea. The gut is a niche for billions of microorganisms that help metabolism and digestion in their symbiotic relationship with the host. Many reports have demonstrated that gut microbiomes have lesser fungal burden contrary to bacterial communities. Fungal composition is about $0.1 \%$ of the gastrointestinal tract microorganisms, and there is an established relationship of antagonism and synergy between fungi, bacteria, and viruses [75]. In the adult individual, the gut microbiome has approximately $10^{14}$ bacteria. The microbes residing in the gut are discrete from the microbes linked to the microbiota of other parts of the host [76]. Many large-scale projects 
such as Metagenomics of the Human Intestinal Tract (MetaHIT) and National Institutes of Health (NIH) Human Microbiome Project examining the gut microbiota have attracted considerable interest due to the abundance and diversity of bacterial microbiota existing in the gut $[22,76]$.

\subsubsection{Microbial Niches of Gut and Gastrointestinal Microbiota}

The majority of bacteria in the gut of healthy persons are associated with the phyla, Bacteroidetes, and Firmicutes (collected 70-90\%) and to a lesser extent, Actinobacteria and Proteobacteria. These phyla represent the core microbiota of the human gut $[23,24]$. Inside the gut ecosystem several factors which include oxygen levels, changes in $\mathrm{pH}$, or macro- and micronutrients variation, affect the variety and abundance of bacterial and fungal species. The gut microbiota helps in the absorption of nutrients and water, and a semipermeable barrier is assembled essentially by enterocytes (intestinal epithelial cells). Ascomycota and Basidiomycota are the common taxa identified in the gut mycobiota from healthy individuals, with leading genera: Saccharomyces, Candida, Malassezia, and Cladosporium [22,25]. In the gastrointestinal (GI) tract of humans, bacterial genera that are most usually found include Clostridium, Streptococcus, and Bacteroides (Table 1). The colon is the leading site for the bacterial fermentation of non-digestible food such as fibers, and it comprises about $70 \%$ of all host bacteria. The studies reported that fungi belong to the phyla Ascomycota, Basidiomycota, and Chytridiomycota are the most common [77]. More consistently found fungi are also restricted, with the genera Candida and Saccharomyces being the prominent ones [26]. The most frequently described genus of Archaea that is found in the GI tract is Methanobrevibacter while others are also been detected including Methanosphaera, $\mathrm{Ni}$ trososphaera, Thermogynomonas, Thermoplasma, and Methanomethylophilus alvus. The solitary diet factor inducing fungal colonization and growth in the GI tract in the presence of Candida spp. are mostly linked with dietary carbohydrates, and not with dietary amino acids, proteins, and fatty acids.

\subsubsection{Candida and Bacteria Interaction in Gut and Gastrointestinal Microbiota}

Generally, most animals, including humans, with intact, healthy microbiota are unaffected by pathogenic fungi, viz. C. albicans colonization [78]. C. albicans is commensal in the human gut, providing an insight into the connections between the fungal and bacterial species in the gut. The occurrence of Firmicutes and Bacteroides appears significant to sustain C. albicans growth persistence in a mouse model of infection [79]. Fungal-bacterial community interaction was shown in mice treated with dextran sulphate sodium (DSS) to induce colitis. In this model, DSS-treatment inhibited growth of C. glabrata, which in turn reduces infection. It directed increased growth of E. coli, E. faecalis, and Bacteroides vulgatus, although Lactobacillus johnsonii, Bacteroides thetaiotaomicron, and Bifidobacterium diminished [80] (Table 1). The strain Saccharomyces cerevisiae boulardii is used as a defensive measure against Clostridium difficile infection. The colonization of $C$. albicans can change the total benefits of commensal enteric bacteria. [81]. S. cerevisiae diminished bacterial growth, reduced colonization, and inverted the attachment of enterotoxigenic E. coli (ETEC) to the host [82]. Salmonella Typhimurium inhibits C. albicans hyphal formation, biofilm, etc. When a SopB (TTSS) knockout mutant is used, this inhibition is lower [83]. C. albicans hyphal growth is regulated by novel role of TOR1 governing the activities of adhesion genes, hinting at the mammalian target of rapamycin (mTOR) signaling pathway [84]. On the other hand, as demonstrated in a peritonitis murine model, fungal-bacterial communication can show synergistic effects on the host through proinflammatory cytokines secretion, with the consequence of cell destruction on the host [85]. Some communities of bacteria and fungi interact with each other and help to colonize the gut and oral cavity. This biofilm comprised of multiple species can provide additional defense against antimicrobial agents and provide host immune evasion [86]. C. albicans infection into mice chemotherapy model induces important changes in gut microbiota diversity. Enterococcus spp., specifically E. faecalis, were found to promote Lactobacillus growth upon subsequent 
infection of C. albicans into the gut of chemotherapy model of mice [87]. In a Caenorhabditis elegans model of infection [88] E. faecalis inhibited C. albicans yeast to hyphal transition by release of proteases involved with quorum sensing. In a mouse model, Lactobacillus and C. albicans may compete with one another [89]. The E. faecalis bacteriocin EntV was recognized as the important inhibitor of hyphal development [90]. C. albicans and E. faecalis are often identified together in nosocomial infections which suggest that $E$. faecalis could utilize alternate mechanisms for accommodating growth with C. albicans. Interestingly, fungi have a role in the gut-brain axis. Fungi are prominent in the bidirectional connections amongst brain and gut through neuro-immuno-endocrine mediators, which is equivalent to microbiome-gut-brain axis [91]. In an in vivo model, a synergistic effect was observed between C. albicans and Streptococci. Streptococci enhances invasion by C. albicans, while C. albicans improves Streptococcus spp. biofilm development in the superior GI mucosa [92]. Similar interactions have been studied between C. albicans, Lactobacillus spp., H. pylori, and Escherichia coli in the GI tract [93]. For instance, the co-cultures of C. albicans with H. pylori increase the disease progression of GI ulcers. Additionally, Lactobacillus spp. inhibit the growth and pathogenesis of $C$. albicans through hydrogen peroxide production, although this inhibition was not sufficient to eliminate C. albicans [94]. Similarly, diverse Lactobacillus species have changed their capabilities in obstructing the growth of C. albicans in the GI tract. Moreover, the variation seen in fungal virulence may be influenced by the impact of Lactobacillus spp. on the host immune response [95]. In the GI tract disruptions of the bacterial community tend to promote $C$. albicans colonization, and this result indicates that the normal homeostasis of the bacterial species in the GI microbiota inhibits fungal expansion and invasion [96]. Saccharomyces boulardii is an exogenous fungal probiotic, extensively used as a probiotic in scientific practice ever since the 1950s in Europe [97].

\subsubsection{Gut and Gastrointestinal Dysbiosis}

Fungal dysbiosis in the gut contributes to the establishment and pathogenesis of several human diseases. Some important factors contribute toward fungal growth progression, which include many gut-related diseases such as inflammatory bowel diseases, Crohn's disease, ulcerative colitis, and gut inflammation [98]. In mice treated with antifungal drugs to induce dysbiosis in the gut, the level of opportunistic fungi like Aspergillus amstelodami, Epicoccum nigrum, and Wallemia sebi increases [27]. It may be possible to associate gut microbiota dysbiosis with digestive tract diseases/diet linked diseases (obesity, inflammatory bowel disease, enterocolitis, diabetes, etc.). Gut dysbiosis is also involved in diseases outside the intestine such as muscular dystrophy, mental disorders, cancers, vaginosis, etc. [99]. Furthermore, gut microbiota dysbiosis have been associated with ocular diseases (which are as remote as the brain), Uveitis, age-related macular degeneration, Sjogrens syndrome-associated dry eye and Keratitis. Fungal dysbiosis influenced by antifungal action affected a selection of fewer, non-Candida fungi that caused deterioration of DSS-induced colitis and exacerbated allergic airway disease [100,101]. Broad-spectrum antibiotic implementation is a unique threat factor for systemic, disseminated candidiasis originating in the gut microbiota as antibiotic treatment diminishes bacteria that normally limit Candida growth [102]. GI dysfunction occurs mainly due to motility and absorption disturbances, mucosal disintegrity, alterations in the microbiome, enhanced intra-abdominal pressure and altered infections of the GI tract. Many reports demonstrated the dysbiosis between the bacterial communities in the GI tract including inflammatory bowel diseases, transplantation, gastric ulcer and gastritis, blood diseases, HIV infection, and other immunodeficiencies and antibiotic associated diarrhea. C. albicans was recovered in the stools of $63 \%$ healthy individuals, $70 \%$ of inpatients, and $91 \%$ of patients with inflammatory bowel disease [103,104]. The colonization of Candida in the GI tract has also been associated with other conditions like diabetes [105]. Some specific opportunistic pathogens such as Aspergillus flavus, Basidibolus ranarum, Cryptococcus noeformans, Exophilia dermatidis, H. Capsulatum, Paracoccidioides brasiliensis, and Penicilliummarneffei were 
found in immunocompromised/immunosuppressed groups and in antibiotic associated diarrhea [106-108].

\subsubsection{Candida and Metabolite Interaction in the Gastrointestinal Tract}

In addition to the wide range of microbiome interactions taking place within the GI tract, metabolites present in the GI tract have a significant role in the colonization and pathogenesis of Candida albicans in the host. A recent metabolomics study conducted by our group using a mouse model of $C$. albicans infection identified significant changes in the gut metabolome as a result of antibiotic treatment [109]. Among the metabolites that were differentially regulated, three prominent groups were identified: carbohydrates and sugar alcohols, bile acids, and short-chain fatty acids (SCFA). Further investigation into each group and their interactions with $C$. albicans revealed a wide range of effects suggesting prominent roles for specific metabolites in promoting or inhibiting C. albicans colonization and pathogenesis.

Primary bile acids, specifically taurocholic acid (TCA) and taurochenodeoxycholic acid (TCDCA) were found to be upregulated in this metabolomics study, and in vitro incubation of $C$. albicans with these metabolites revealed a significant increase in fungal growth and hyphal morphogenesis [109-111]. Further, carbohydrates and sugar alcohols significantly promoted the fungal growth and morphogenesis in vitro. In contrast, the levels of secondary bile acids in the metabolomics study were decreased, and multiple studies have identified secondary bile acid such as deoxycholic acid (DCA), hyodeoxycholic acid (HDCA), ursodeoxycholic acid (UDCA), and lithocholic acid (LCA) as inhibitory for in vitro C. albicans growth as well as inhibiting hyphal formation in vitro and ex vivo $[109,111,112]$. The secondary bile acids LCA and DCA were also found to inhibit biofilm formation and pre-treatment of HCT116 cells with these bile acids reduced C. albicans attachment [112]. SCFA levels are also decreased during antibiotic treatment, and in vitro growth of $C$. albicans is inhibited by SCFAs such as acetic acid, butyric acid, and propionic acid. This study also demonstrated that these SCFAs reduce in vitro hyphal formation and reduce metabolic activity of C. albicans biofilms [113]. Taken together, emerging evidence indicate that gut metabolites differentially control the fungal growth and hyphal morphogenesis. Additional investigation is needed to dissect how these metabolites regulate fungal colonization and pathogenesis, to better understand fungal commensalism and pathogenicity and to develop novel therapeutic approaches.

\subsection{Vaginal Mycobiota and Dysbiosis}

The female vaginal tract of healthy women of childbearing age comprises mainly of Lactobacillus which is the first line of defense against pathogens. Additionally, there are fungal communities that exist within the interior female reproductive tract. The three fungal phyla identified in vaginal sections are Ascomycota (in which Candida is the main genera), Basidiomycota, and Oomycota [114] (Table 1). Many studies showed that the composition of the fungal mycobiota of the vagina has great significance because its disturbance is the leading cause of many vaginal infections. These infections comprise bacterial vaginosis, vulvovaginal candidiasis, aerobic vaginitis, chlamydia infection, gonorrhea, and other sexually transmitted diseases including human immunodeficiency virus (HIV). Bacterial vaginosis and vulvovaginal candidiasis are the most prominent infections disturbing the female reproductive tract $[115,116]$. Bacterial vaginosis is of particular concern for pregnant women as it increases risk for preterm delivery, maternal infectious morbidity and a resilient hazard for late miscarriage [117].

\subsubsection{Microbial Niches of Vaginal Mycobiota}

The organization of the vaginal bacterial and fungal species of fit women is complex due to variations associated with menstruation, pregnancy, and health prominence. The vaginal niche of a healthy women is distinctly acidic ( $\mathrm{pH}$ of 4.5 or less), which is mainly due to the occurrence of lactic acid producing bacteria that survive in the anaerobic 
conditions [118]. The hormone-dependent glycogen produced by human vaginal epithelial cells and other nutrients including lactate contribute to fungal colonization. Candida is extremely flexible regarding shifts in the nutrients available in the vagina. The native vaginal microbiota mainly is a consolidation of genera Lactobacillus, Gardnerella, Atopobium, Prevotella, Streptococcus, Ureaplasma, Escherichia, Mycoplasma, Staphylococcus Candida, Megasphaera, and many others [29]. Among these, Lactobacillus spp. is the vital member of the vaginal microbiota, which ensures a healthy niche. Candida species are normal component of their vaginal microbiota (e.g., C. tropicalis, C. pseudotropicalis, C. stellatoidea, C. krusei, C. guilliermondii, and C. albicans).

\subsubsection{Candida and Bacteria Interaction in Vaginal Microbiota}

Lactobacillus in the vaginal microbiota is largely associated with protecting the vaginal mucosa and creating a healthy microenvironment. Decreased Lactobacillus spp. is associated with vulnerability to multiple diseases, including bacterial vaginosis, urinary tract infections, vulvovaginal candidiasis, and other urogenital infections. Lactobacilli are believed to inhibit $C$. albicans by numerous mechanisms. Lactobacilli compete with C. albicans for limited nutrients and adherence sites, reducing growth, along with preventing hyphal development [119]. C. albicans attachment to vaginal epithelial is diminished during co-colonization with multiple Lactobacillus spp. [120]. A bacteriocin-like peptide produced by multiple L. crispatus and L. jensenii strains influence pseudohyphae formation and inhibited growth of C. albicans from healthy premenopausal women [121]. L. crispatus can reduce $C$. albicans virulence and increase the local immune response by promoting immune modulating cytokines profile, i.e., upregulating IL-2, IL-6, and IL-17 and downregulating IL-8 [122]. Additionally, some studies showed that C. albicans is susceptible to lactic acid at low $\mathrm{pH}$. They proposed that lactic acid invades through the fungal plasma membrane at lower $\mathrm{pH}$ levels where it separates into protons and lactic acid [123]. The ions acidify the cytosol and restrict the cell metabolism. Moreover, lactobacilli also reduce C. albicans virulence factors by the inhibition of hyphae growth [124]. An in vivo study by using the nematode model Caenorhabditis elegans, showed that L. paracasei repressed C. albicans hyphae growth. Similarly, Galleria mellonella larvae treated with L. rhamnosus enhanced survival after C. albicans infection and reduced fungal colony forming units [125]. Candida-bacteria connections inside the vagina are likely to occur in the interior context of a polymicrobial biofilm on the epithelial surface. The synergistic association between C. albicans and Group B streptococci and Escherichia coli is harmful for the host. Some studies validated an in vitro model with vaginal epithelial cells where Group B streptococci and C. albicans synergistically improved their ability to reside with the host cells [126].

\section{Targeted Microbial Therapy}

Microbiota restoration strategies are required for treatment which allow beneficial bacteria to propagate, eliminate colonization by opportunistic pathogens, and enhances resistance to colonization by pathogens. Prebiotics can affect the bacterial population by benefitting the host through specific environmental or direct interactions with pathogenic microbes and immune cell carbohydrate receptors. Neutrophil phagocytosis is initiated through receptors on phagocytes and natural killer cells that bind $\beta$-glucans on Candida cell walls. Additionally, prebiotics encourage health by supporting the production of metabolites, e.g., folate, indoles, secondary bile acids, and short-chain fatty acids. Prebiotic treatment helps in selective upsurge/drop in specific microbiota bacteria that ultimately can induce health benefits [127]. They modulate the microbiota and exert a downstream effect on host health. Probiotics are getting hold of extensive inclusion as novel prevention strategies or treatments for a wide range of diseases, as validated by many studies. Mechanisms of probiotics comprise restoration of microbial populations and destruction of pathogens, increase of anti-inflammatory cytokines and suppression of proinflammatory cytokines along with improvement of immunity [128]. How probiotics may mediate such beneficial effects, including direct inhibition of pathogens, has been demonstrated by sev- 
eral mechanisms. Postbiotic supplementation derived from Lactobacillus paracasei was able to protect $G$. mellonella infected with $C$. auris and immunomodulate indicating a dual role in modulating host immune response [129]. Even meta-analysis is among the first study of such kind which establishes the effect of probiotics on oral candidiasis [130].

\section{Microbiota Transplant}

Fecal microbiota transplantation (FMT) is the transmittance of donor microbiota inoculum such that damaged microbiota is restored. It has been recently successfully applied to ulcerative colitis where the intestinal microbiota of the patients sustains severe damage from multiple rounds of antibiotic treatment. This strategy works on an organ or tissue "transplant" therapeutic model and recognizes microbiota as a complex unit. FMT reduces Candida by suppressing pro-inflammatory immune responses during intestinal disease [131]. Another study revealed that FMT is effective in preventing Candida colonization of the GI tract [132]. However, this is a provisional strategy until an actual drug product is approved to fulfill the unmet need.

\section{Conclusions}

There are limited studies unravelling the mystery regarding the composition and diversity of human microbiota and its interrelation with Candida infections. The current scenario reveals a need for comparative genomics-based studies on pathogens to enlighten our rudimentary understanding of fungal pathogenesis. Similarly, targeted microbial therapy and microbial transplant are novel methods that are yet to be explored to their potential. In silico metabolic interaction predictions can also lead to identification of microbiome features affecting Candida colonization. Comprehending these factors may help in the development of a better perception of how antagonistic and synergetic microbial interactions influence Candida infections so that targeted microbial therapy could be employed.

Author Contributions: Conceptualization, S.H. (Saif Hameed) and Z.F.; methdology, S.H. (Sandeep Hans) and R.M.; investigation, S.H. (Sandeep Hans) and R.M.; writing-original draft preparation, S.H. (Sandeep Hans); writing-review and editing, S.H. (Saif Hameed), Z.F., S.H. (Sandeep Hans), S.T. and R.M.; supervision, S.H. (Saif Hameed), Z.F. and S.T. All authors have read and agreed to the published version of the manuscript.

Funding: This research received no external funding.

Data Availability Statement: All data presented in this study are available in this manuscript.

Conflicts of Interest: The authors declare no conflict of interest.

\section{References}

1. Shoham, S.; Levitz, S.M. The Immune Response to Fungal Infections. Br. J. Haematol. 2005, 129, 569-582. [CrossRef] [PubMed]

2. Hazen, K.C. New and Emerging Yeast Pathogens. Clin. Microbiol. Rev. 2005, 8, 462-478. [CrossRef]

3. Fridkin, S.K.; Jarvis, W.R. Epidemiology of Nosocomial Fungal Infections. Clin. Microbiol. Rev. 1996, 9, 499-511. [CrossRef] [PubMed]

4. Barnett, J.A. A History of Research on Yeasts 2: Louis Pasteur and His Contemporaries, 1850-1880. Yeast 2000, 16, 755-771. [CrossRef]

5. Pfaller, M.; Wenzel, R. Impact of the changing epidemiology of fungal infections in the 1990s. Eur. J. Clin. Microbiol. Infect. Dis. 1992, 11, 287-291. [CrossRef]

6. Pfaller, M.A. Epidemiology and Control of Fungal Infections. Clin. Infect. Dis. 1994, 19, S8-S13. [CrossRef] [PubMed]

7. Shapiro, R.S.; Robbins, N.; Cowen, L.E. Regulatory Circuitry Governing Fungal Development, Drug Resistance, and Disease. Microbiol. Mol. Biol. Rev. 2011, 75, 213-267. [CrossRef]

8. Mba, I.E.; Nweze, E.I. Mechanism of Candida pathogenesis: Revisiting the vital drivers. Eur. J. Clin. Microbiol. Infect. Dis. 2020, 39, 1797-1819. [CrossRef] [PubMed]

9. Kalia, N.; Singh, J.; Kaur, M. Microbiota in vaginal health and pathogenesis of recurrent vulvovaginal infections: A critical review. Ann. Clin. Microbiol. Antimicrob. 2020, 19, 5. [CrossRef]

10. Deo, P.N.; Deshmukh, R. Oral microbiome: Unveiling the fundamentals. J. Oral. Maxillofac. Pathol. 2019, 23, 122-128.

11. Zaura, E.; Nicu, E.A.; Krom, B.P.; Keijser, B.J. Acquiring and maintaining a normal oral microbiome: Current perspective. Front. Cell Infect. Microbiol. 2015, 4, 85. [CrossRef] [PubMed] 
12. Huse, S.M.; Ye, Y.; Zhou, Y.; Fodor, A.A. A core human microbiome as viewed through $16 \mathrm{~S}$ rRNA sequence clusters. PLoS ONE 2012, 7, e34242. [CrossRef] [PubMed]

13. Klimesova, K.; Jiraskova Zakostelska, Z.; Tlaskalova-Hogenova, H. Oral bacterial and fungal microbiome impacts colorectal carcinogenesis. Front. Microbiol. 2018, 9, 774. [CrossRef] [PubMed]

14. Falsetta, M.L.; Klein, M.I.; Colonne, P.M.; Scott-Anne, K.; Gregoire, S.; Pai, C.-H.; Gonzalez-Begne, M.; Watson, G.; Krysan, D.J.; Bowen, W.H. Symbiotic relationship between Streptococcus mutans and Candida albicans synergizes virulence of plaque biofilm in vivo. Infect. Immun. 2014, 82, 1968-1981. [CrossRef]

15. Dupuy, A.K.; David, M.S.; Li, L.; Heider, T.N.; Peterson, J.D.; Montano, E.A.; Dongari-Bagtzoglou, A.; Diaz, P.I.; Strausbaugh, L.D. Redefining the human oral mycobiome with improved practices in amplicon-based taxonomy: Discovery of Malassezia as a prominent commensal. PLoS ONE 2014, 9, e90899. [CrossRef] [PubMed]

16. Ghannoum, M.A.; Jurevic, R.J.; Mukherjee, P.K.; Cui, F.; Sikaroodi, M.; Naqvi, A.; Gillevet, P.M. Characterization of the oral fungal microbiome (mycobiome) in healthy individuals. PLoS Pathog. 2010, 6, e1000713. [CrossRef] [PubMed]

17. Moissl-Eichinger, C.; Pausan, M.; Taffner, J.; Berg, G.; Bang, C.; Schmitz, R.A. Archaea are interactive components of complex microbiomes. Trends Microbiol. 2018, 26, 70-85. [CrossRef] [PubMed]

18. Dridi, B.; Raoult, D.; Drancourt, M. Archaea as emerging organisms in complex human. Microbiomes 2011, 17, 56-63.

19. Woo, S.B.; Challacombe, S.J. Management of recurrent oral herpes simplex infections. Oral Surg. Oral Med. Oral Pathol. Oral Radiol. Endod. 2007, 103, S12-S18. [CrossRef] [PubMed]

20. Bogaert, D.; Keijser, B.; Huse, S.; Rossen, J.; Veenhoven, R.; van Gils, E. Variability and diversity of nasopharyngeal microbiota in children: A metagenomic analysis. PLoS ONE 2011, 6, e17035. [CrossRef]

21. Stearns, J.C.; Davidson, C.J.; McKeon, S.; Whelan, F.J.; Fontes, M.E.; Schryvers, A.B.; Bowdish, D.M.; Kellner, J.D.; Surette, M.G. Culture and molecular-based profiles show shifts in bacterial communities of the upper respiratory tract that occur with age. ISME J. 2015, 9, 1268. [CrossRef]

22. Qin, J.; Li, R.; Raes, J.; Arumugam, M.; Burgdorf, K.S.; Manichanh, C.; Nielsen, T.; Pons, N.; Levenez, F.; Amada, T. A human gut microbial gene catalogue established by metagenomic sequencing. Nature 2010, 464, 59. [CrossRef] [PubMed]

23. Aas, J.; Gessert, C.E.; Bakken, J.S. Recurrent Clostridium difficile colitis: Case series involving 18 patients treated with donor stool administered via a nasogastric tube. Clin. Infect. Dis. 2003, 36, 580-585. [CrossRef] [PubMed]

24. Ravel, J.; Gajer, P.; Abdo, Z.; Schneider, G.M.; Koenig, S.S.K.; McCulle, S.L. Vaginal microbiome of reproductive-age women. Proc. Natl. Acad. Sci. USA 2011, 108, 4680-4687. [CrossRef] [PubMed]

25. Bhute, S.; Pande, P.; Shetty, S.A.; Shelar, R.; Mane, S.; Kumbhare, S.V.; Gawali, A.; Makhani, H.; Navandar, M.; Dhotre, D.; et al. Molecular Characterization and Meta-Analysis of Gut Microbial Communities Illustrate Enrichment of Prevotella and Megasphaera in Indian Subjects. Front. Microbiol. 2016, 7, 660. [CrossRef] [PubMed]

26. Hoffmann, C.; Dollive, S.; Grunberg, S.; Chen, J.; Li, H.; Wu, G.D.; Lewis, D.; Bushman, F.D. Archaea and fungi of the human gut icrobiome: Correlations with diet and bacterial residents. PLoS ONE 2013, 8, e66019. [CrossRef] [PubMed]

27. Wheeler, M.L.; Limon, J.J.; Bar, A.S.; Leal, C.A.; Gargus, M.; Tang, J.; Brown, J.; Funari, V.A.; Wang, H.L.; Crother, T.R.; et al. Immunological Consequences of Intestinal Fungal Dysbiosis. Cell Host Microbe 2016, 8, 865-873. [CrossRef] [PubMed]

28. Guo, Y.; Wei, C.; Liu, C.; Li, D.; Sun, J.; Huang, H.; Zhou, H. Inhibitory effects of oral Actinomyces on the proliferation, virulence and biofilm formation of Candida albicans. Arch. Oral Biol. 2015, 60, 1368-1374. [CrossRef]

29. Drell, T.; Lillsaar, T.; Tummeleht, L.; Simm, J.; Aaspõllu, A.; Väin, E.; Saarma, I.; Salumets, A.; Donders, G.G.; Metsis, M. Characterization of the vaginal micro- and mycobiome in asymptomatic reproductive-age Estonian women. PLoS ONE 2013, 8, e54379. [CrossRef]

30. Diop, K.; Mediannikov, O.; Raoult, D.; Bretelle, F.; Fenollar, F. “Vaginella massiliensis” gen. nov., sp. nov., a new genus cultivated from human female genital tract. New Microbes New Infect. 2017, 15, 18-20. [CrossRef]

31. Gross, E.L.; Beall, C.J.; Kutsch, S.R.; Firestone, N.D.; Leys, E.J.; Griffen, A.L. Beyond Streptococcus mutans: Dental caries onset linked to multiple species by $16 \mathrm{~S}$ rRNA community analysis. PLoS ONE 2012, 7, e47722. [CrossRef] [PubMed]

32. Hwang, G.; Liu, Y.; Kim, D.; Li, Y.; Krysan, D.J.; Koo, H. Candida albicans mannans mediate Streptococcusmutans exoenzyme GtfB binding to modulate cross-kingdom biofilm development in vivo. PLoS Pathog. 2017, 13, e1006407. [CrossRef] [PubMed]

33. He, J.; Kim, D.; Zhou, X.; Ahn, S.J.; Burne, R.A.; Richards, V.P.; Koo, H. RNA-seq reveals enhanced sugar metabolism in Streptococcus mutans co-cultured with Candida albicans within mixed-species biofilms. Front. Microbiol. 2017, 8, 1036. [CrossRef] [PubMed]

34. Krzysciak, W.; Koscielniak, D.; Papiez, M.; Vyhouskaya, P.; Zagorska-Swiezy, K.; Kolodziej, I.; Bystrowska, B.; Jurczak, A. Effect of a lactobacillus salivarius probiotic on a double-species Streptococcus mutans and Candida albicans caries biofilm. Nutrients 2017, 9, 1242. [CrossRef] [PubMed]

35. Kim, D.; Sengupta, A.; Niepa, T.H.R.; Lee, B.-H.; Weljie, A.; Freitas-Blanco, V.S.; Murata, R.M.; Stebe, K.J.; Lee, D.; Koo, H. Candida albicans stimulates Streptococcus mutans microcolony development via cross-kingdom biofilm-derived metabolites. Sci. Rep. 2017, 7, 41332. [CrossRef] [PubMed]

36. Barbosa, J.O.; Rossoni, R.D.; Vilela, S.F.; de Alvarenga, J.A.; Velloso, M.; Prata, M.C.; Jorge, A.O.; Junqueira, J.C. Streptococcus mutans can modulate biofilm formation and attenuate the virulence of Candida albicans. PLoS ONE 2016, 11, e0150457. [CrossRef] [PubMed] 
37. Yang, C.; Scoffield, J.; Wu, R.; Deivanayagam, C.; Zou, J.; Wu, H. Antigen I/II mediates interactions between Streptococcus mutans and Candida albicans. Mol. Oral Microbiol. 2018, 33, 283-291. [CrossRef]

38. Zheng, W.; Tan, T.K.; Paterson, I.C.; Mutha, N.V.; Siow, C.C.; Tan, S.Y.; Old, L.A.; Jakubovics, N.S.; Choo, S.W. Streptobase: An oral Streptococcus mitis group genomic resource and analysis platform. PLoS ONE 2016, 11, e0151908. [CrossRef] [PubMed]

39. Xu, H.; Sobue, T.; Bertolini, M.; Thompson, A.; Dongari-Bagtzoglou, A. Streptococcus oralis and Candida albicans synergistically activate _-calpain to degrade e-cadherin from oral epithelial junctions. J. Infect. Dis. 2016, 214, 925-934. [CrossRef] [PubMed]

40. Bamford, C.V.; d'Mello, A.; Nobbs, A.H.; Dutton, L.C.; Vickerman, M.M.; Jenkinson, H.F. Streptococcus gordonii modulates Candida albicans biofilm formation through intergeneric communication. Infect. Immun. 2009, 77, 3696-3704. [CrossRef] [PubMed]

41. Diaz, P.I.; Xie, Z.; Sobue, T.; Thompson, A.; Biyikoglu, B.; Ricker, A.; Ikonomou, L.; Dongari-Bagtzoglou, A. Synergistic interaction between Candida albicans and commensal oral streptococci in a novel in vitro mucosal model. Infect. Immun. 2012, 80, 620-632. [CrossRef]

42. Ma, S.; Li, H.; Yan, C.; Wang, D.; Li, H.; Xia, X.; Dong, X.; Zhao, Y.; Sun, T.; Hu, P. Antagonistic effect of protein extracts from Streptococcus sanguinis on pathogenic bacteria and fungi of the oral cavity. Exp. Ther. Med. 2014, 7, 1486-1494. [CrossRef] [PubMed]

43. Bor, B.; Cen, L.; Agnello, M.; Shi, W.; He, X. Morphological and physiological changes induced by contact-dependent interaction between Candida albicans and Fusobacterium nucleatum. Sci. Rep. 2016, 6, 27956. [CrossRef]

44. Karkowska-Kuleta, J.; Bartnicka, D.; Zawrotniak, M.; Zielinska, G.; Kieronska, A.; Bochenska, O.; Ciaston, I.; Koziel, J.; Potempa J.; Baster, Z. The activity of bacterial peptidylarginine deiminase is important during formation of dual-species biofilm by periodontal pathogen Porphyromonas gingivalis and opportunistic fungus Candida albicans. Pathog. Dis. 2018, 76, fty033. [CrossRef]

45. Haverman, T.M.; Laheij, A.; de Soet, J.J.; de Lange, J.; Rozema, F.R. Candida and Porphyromonas gingivalis: The effect on wound closure in vitro. J. Oral Microbiol. 2017, 9, 1328266. [CrossRef]

46. Elving, G.J.; van Der Mei, H.C.; Busscher, H.J.; van Weissenbruch, R.; Albers, F.W. Air-flow resistances of silicone rubber voice prostheses after formation of bacterial and fungal biofilms. J. Biomed. Mater. Res. 2001, 58, 421-426. [CrossRef]

47. Ohara-Nemoto, Y.; Haraga, H.; Kimura, S.; Nemoto, T.K. Occurrence of staphylococci in the oral cavities of healthy adults and nasal oral trafficking of the bacteria. J. Med. Microbiol. 2008, 57, 95-99. [CrossRef]

48. Baena-Monroy, T.; Moreno-Maldonado, V.; Franco-Martinez, F.; Aldape-Barrios, B.; Quindos, G.; Sanchez-Vargas, L.O. Candida albicans, Staphylococcus aureus and Streptococcus mutans colonization in patients wearing dental prosthesis. Med. Oral Patol. Oral Cir. Bucal. 2005, 10, E27-E39.

49. MacFarlane, T.W.; Helnarska, S.J. The microbiology of angular cheilitis. Br. Dent. J. 1976, 140, 403-406. [CrossRef] [PubMed]

50. Wade, W.G. The oral microbiome in health and disease. Pharmacol. Res. 2013, 69, 137-143. [CrossRef] [PubMed]

51. Marsh, P.D.; Zaura, E. Dental biofilm: Ecological interactions in health and disease. J. Clin. Periodontol. 2017, 44, S12-S22. [CrossRef] [PubMed]

52. Zhang, Y.; Wang, X.; Li, H.; Ni, C.; Du, Z.; Yan, F. Human oral microbiota and its modulation for oral health. Biomed. Pharmacother. 2018, 99, 883-893. [CrossRef] [PubMed]

53. Mira, A.; Simon-Soro, A.; Curtis, M.A. Role of microbial communities in the pathogenesis of periodontal diseases and caries. $J$. Clin. Periodontol. 2017, 44, S23-S38. [CrossRef]

54. Costa, A.C.; Pereira, C.A.; Junqueira, J.C.; Jorge, A.O. Recent mouse and rat methods for the study of experimental oral candidiasis. Virulence 2013, 4, 391-399. [CrossRef] [PubMed]

55. Palacio, A.; Villar, J.; Alhambra, A. Epidemiology of invasive candidiasis in pediatric and adult population. Rev. Iberoam. Micol. 2009, 26, 2-7. [CrossRef]

56. Van den Bergh, M.R.; Biesbroek, G.; Rossen, J.W.A.; de Steenhuijsen Piters, W.A.A.; Bosch, A.A.T.M.; van Gils, E.J.M. Associations between pathogens in the upper respiratory tract of young children: Interplay between viruses and bacteria. PLoS ONE 2012, 7, e47711.

57. Lewnard, J.A.; Huppert, A.; Givon-Lavi, N.; Pettigrew, M.M.; Regev-Yochay, G.; Dagan, R. Density, serotype diversity, and fitness of Streptococcus pneumoniae in upper respiratory tract cocolonization with nontypeable Haemophilus influenzae. J. Infect. Dis. 2016, 214, 1411-1420. [CrossRef]

58. Shak, J.R.; Vidal, J.E.; Klugman, K.P. Influence of bacterial interactions on pneumococcal colonization of the nasopharynx. Trends Microbiol. 2013, 21, 129-135. [CrossRef]

59. Chien, Y.-W.; Vidal, J.E.; Grijalva, C.G.; Bozio, C.; Edwards, K.M.; Williams, J.V.; Griffin, M.R.; Verastegui, H.; Hartinger, S.M.; Gil, A.I.; et al. Density interactions among Streptococcus pneumoniae, Haemophilus influenzae and Staphylococcus aureus in the nasopharynx of young peruvian children. Pediatr. Infect. Dis. J. 2013, 32, 72-77. [CrossRef]

60. Tan, T.T.; Mörgelin, M.; Forsgren, A.; Riesbeck, K. Haemophilus influenzae survival during complement-mediated attacks is promoted by Moraxella catarrhalis outer membrane vesicles. J. Infect. Dis. 2007, 195, 1661-1670. [CrossRef]

61. Liu, C.M.; Price, L.B.; Hungate, B.A.; Abraham, A.G.; Larsen, L.A.; Christensen, K.; Stegger, M.; Skov, R.; Andersen, P.S. Staphylococcus aureus and the ecology of the nasal microbiome. Sci. Adv. 2015, 1, e1400216. [CrossRef] [PubMed] 
62. Yan, M.; Pamp, S.J.; Fukuyama, J.; Hwang, P.H.; Cho, D.-Y.; Holmes, S.; Relman, D.A. Nasal microenvironments and interspecific interactions influence nasal microbiota complexity and S. aureus carriage. Cell Host Microbe 2013, 14, 631-640. [CrossRef] [PubMed]

63. Bittinger, K.; Charlson, E.S.; Loy, E.; Shirley, D.J.; Haas, A.R.; Laughlin, A.; Yi, Y.; Wu, G.D.; Lewis, J.D.; Frank, I.; et al. Improved characterization of medically relevant fungi in the human respiratory tract using next-generation sequencing. Genome Biol. 2014, 15, 487. [CrossRef]

64. Kieninger, E.; Singer, F.; Tapparel, C.; Alves, M.P.; Latzin, P.; Tan, H.-L.; Bossley, C.; Casaulta, C.; Bush, A.; Davies, J.C.; et al. High rhinovirus burden in lower airways of children with cystic fibrosis. Chest 2013, 143, 782-790. [CrossRef]

65. Roux, D.; Gaudry, S.; Dreyfuss, D.; El-Benna, J.; de Prost, N.; Denamur, E. Candida albicans impairs macrophage function and facilitates Pseudomonas aeruginosa pneumonia in rat. Crit. Care Med. 2009, 37, 1062-1067. [CrossRef]

66. Xu, H.; Sobue, T.; Thompson, A.; Xie, Z.; Poon, K.; Ricker, A.; Cervantes, J.; Diaz, P.I.; Dongari-Bagtzoglou, A. Streptococcal co-infection augments Candida pathogenicity by amplifying the mucosal inflammatory response. Cell. Microbiol. 2013, 16, 214-231. [CrossRef]

67. Zapata, H.J.; Quagliarello, V.J. The microbiota and microbiome in aging: Potential implications in health and age-related diseases. J. Am. Geriatr. Soc. 2015, 63, 776-781. [CrossRef] [PubMed]

68. Flamaing, J.; Peetermans, W.E.; Vandeven, J.; Verhaegen, J. Pneumococcal colonization in older persons in a nonoutbreak setting. J. Am. Geriatr. Soc. 2010, 58, 396-398. [CrossRef] [PubMed]

69. Thevaranjan, N.; Whelan, F.J.; Puchta, A.; Ashu, E.; Rossi, L.; Surette, M.G.; Bowdish, D.M. Streptococcus pneumoniae colonization disrupts the microbial community within the upper respiratory tract of aging mice. Infect. Immun. 2016, 84, 906-916. [CrossRef] [PubMed]

70. Cremers, A.J.H.; Zomer, A.L.; Gritzfeld, J.F.; Ferwerda, G.; van Hijum, S.A.F.T.; Ferreira, D.M.; Shak, J.R.; Klugman, K.P.; Boekhorst, J.; Timmerman, H.M.; et al. The adult nasopharyngeal microbiome as a determinant of pneumococcal acquisition. Microbiome 2014, 2, 44. [CrossRef]

71. Murphy, T.F.; Parameswaran, G.I. Moraxella catarrhalis, a human respiratory tract pathogen. Clin. Infect. Dis. 2009, 49, 124-131. [CrossRef] [PubMed]

72. Hays, J. The Genus Moraxella. In The Prokaryotes, 3rd ed.; Dworkin, M., Rosenberg, E., Falkow, S., Schleifer, K., Eds.; Springer: New York, NY, USA, 2006; pp. 958-987.

73. Riley, T.V.; Pingault, N.M. Moraxella. In Molecular Typing in Bacterial Infections, 1st ed.; De Filippis, I., McKee, M., Eds.; Humana Press: New York, NY, USA, 2013; p. 482.

74. Kobayashi, Y. Bacteremic Moraxella catarrhalis pneumonia. J. Infect. Chemother. 2000, 6, 68. [CrossRef] [PubMed]

75. Wang, Z.K.; Yang, Y.S.; Stefka, A.T.; Sun, G.; Peng, L.H. Fungal microbiota and digestive diseases. Aliment Pharmacol. Ther. 2014, 39, 751-766. [CrossRef]

76. Peterson, J.; Garges, S.; Giovanni, M.; McInnes, P.; Wang, L.; Schloss, J.A.; Bonazzi, V.; McEwen, J.E.; Wetterstrand, K.A.; Deal, C.; et al. The NIH Human Microbiome Project. Genome Res. 2010, 19, 2317-2323.

77. Wheeler, M.L.; Limon, J.J.; Underhill, D.M. Immunity to commensal fungi: Detente and disease. Annu. Rev. Pathol. 2016, 12, 359-385. [CrossRef] [PubMed]

78. Van der Waaij, D.; Vries, J.M.B.-D.; der Wees, J.E.C.L.-V. Colonization resistance of the digestive tract in onventional and antibiotic-treated mice. J. Hyg. 1971, 69, 405-411. [CrossRef] [PubMed]

79. Erb-Downward, J.R.; Falkowski, N.R.; Mason, K.L.; Muraglia, R.; Hufnagle, G.B. Modulation of post-antibiotic bacterial community reassembly and host response by Candida albicans. Sci. Rep. 2013, 3, 2191. [CrossRef] [PubMed]

80. Charlet, R.; Pruvost, Y.; Tumba, G.; Istel, F.; Poulain, D.; Kuchler, K.; Sendid, B.; Jawhara, S. Remodeling of the Candida glabrata cell wall in the gastrointestinal tract aspects the gut microbiota and the immune response. Sci. Rep. 2018, 8, 3316. [CrossRef]

81. Jiang, T.T.; Shao, T.Y.; Ang, W.G.; Kinder, J.M.; Turner, L.H.; Pham, G.; Whitt, J.; Alenghat, T.; Way, S.S. Commensal fungi recapitulate the protective benefits of intestinal bacteria. Cell Host Microbe 2017, 22, 809-816. [CrossRef]

82. Roussel, C.; Sivignon, A.; de Vallée, A.; Garrait, G.; Denis, S.; Tsilia, V.; Ballet, N.; Vandekerckove, P.; Van de Wiele, T.; Barnich, N. Anti-infectious properties of the probiotic Saccharomyces cerevisiae CNCM I-3856 on enterotoxigenic E. coli (ETEC) strain H10407. Appl. Microbiol. Biotechnol. 2018, 102, 6175-6189. [CrossRef]

83. Kim, Y.; Mylonakis, E. Killing of Candida albicans filaments by Salmonella enterica serovar Typhimurium is mediated by SopB e_ectors, parts of a type III secretion system. Eukaryot. Cell 2011, 10, 782-790. [CrossRef]

84. Bastidas, R.J.; Heitman, J.; Cardenas, M.E. The protein kinase Tor1 regulates adhesin gene expression in Candida albicans. PLoS Pathog. 2009, 5, e1000294. [CrossRef] [PubMed]

85. Peters, B.M.; Noverr, M.C. Candida albicans-Staphylococcus aureus polymicrobial peritonitis modulates host innate immunity. Infect. Immun. 2013, 81, 2178-2189. [CrossRef]

86. Ghannoum, M. Cooperative evolutionary strategy between the bacteriome and mycobiome. MBio 2010, 7, 6. [CrossRef]

87. Bertolini, M.; Ranjan, A.; Thompson, A.; Diaz, P.I.; Sobue, T.; Maas, K.; Dongari-Bagtzoglou, A. Candida albicans induces mucosal bacterial dysbiosis that promotes invasive infection. PLoS Pathog. 2019, 15, e1007717. [CrossRef] [PubMed]

88. Cruz, M.R.; Graham, C.E.; Gagliano, B.C.; Lorenz, M.C.; Garsin, D.A. Enterococcus faecalis inhibits hyphal morphogenesis and virulence of Candida albicans. Infect. Immun. 2013, 81, 189-200. [CrossRef] [PubMed] 
89. Graf, K.; Last, A.; Gratz, R.; Allert, S.; Linde, S.; Westermann, M.; Gröger, M.; Mosig, A.S.; Gresnigt, M.S.; Hube, B. Keeping Candida commensal: How lactobacilli antagonize pathogenicity of Candida albicans in an in vitro gut model. Dis. Model Mech. 2019, 12, dmm039719. [CrossRef] [PubMed]

90. Graham, C.E.; Cruz, M.R.; Garsin, D.A.; Lorenz, M.C. Enterococcus faecalis bacteriocin EntV inhibits hyphal morphogenesis, biofilm formation, and virulence of Candida albicans. Proc. Natl. Acad. Sci. USA 2017, 114, 4507-4512. [CrossRef]

91. Carabotti, M.; Scirocco, A.; Maselli, M.A.; Severi, C. The gut-brain axis: Interactions between enteric microbiota, central and enteric nervous systems. Ann. Gastroenterol. 2015, 28, 203-209. [PubMed]

92. Souza, J.G.S.; Bertolini, M.; Thompson, A.; Barão, V.A.R.; Dongari-Bagtzoglou, A. Biofilm Interactions of Candida albicans and Mitis Group Streptococci in a Titanium-Mucosal Interface Model. Appl. Environ. Microbiol. 2020, 86, e02950-19. [CrossRef] [PubMed]

93. Cerbo, A.D.; Aponte, M.; Morales-Medina, J.C.; Iannitti, T. Mechanisms and therapeutic effectiveness of lactobacilli. J. Clin. Pathol. 2013, 69, 187-203. [CrossRef]

94. Vasquez, A.; Jakobsson, T.; Ahrne, S.; Forsum, U.; Molin, G. Vaginal Lactobacillus flora of healthy Swedish women. J. Clin. Microbiol. 2002, 40, 2746-2749. [CrossRef]

95. Shankar, J.; Solis, N.V.; Mounaud, S.; Szpakowski, S.; Liu, H.; Losada, L.; Nierman, W.C.; Filler, S.G. Using bayesian modelling to investigate factors governing antibiotic-induced Candida albicans colonization of the gi tract. Sci. Rep. 2015, 5, 8131. [CrossRef]

96. Mason, K.L.; Erb Downward, J.R.; Falkowski, N.R.; Young, V.B.; Kao, J.Y.; Huffnagle, G.B. Interplay between the gastric bacterial microbiota and Candida albicans during postantibiotic recolonization and gastritis. Infect. Immun. 2012, 80, 150-158. [CrossRef] [PubMed]

97. Kelesidis, T.; Pothoulakis, C. Efficacy and safety of the probiotic Saccharomyces boulardii for the prevention and therapy of gastrointestinal disorders. Therap. Adv. Gastroenterol. 2012, 5, 111-125. [CrossRef] [PubMed]

98. Zuo, T.; Ng, S.C. The Gut Microbiota in the Pathogenesis and Therapeutics of Inflammatory Bowel Disease. Front. Microbiol. 2018, 25, 2247. [CrossRef] [PubMed]

99. Tlaskalova-Hogenova, H.; Stepankova, R.; Kozakova, H.; Hudcovic, T.; Vannucci, L.; Tuckova, L. The role of gut microbiota (commensal bacteria) and the mucosal barrier in the pathogenesis of inflammatory and autoimmune diseases and cancer: Contribution of germ-free and gnotobiotic animal models of human diseases. Cell Mol. Immunol. 2011, 8, 110-120. [CrossRef]

100. Kalyana Chakravarthy, S.; Jayasudha, R.; Ranjith, K.; Dutta, A.; Pinna, N.K.; Mande, S.S.; Sharma, S.; Garg, P.; Murthy, S.I.; Shivaji, S. Alterations in the gut bacterial microbiome in fungal Keratitis patients. PLoS ONE 2018, 13, e0199640. [CrossRef] [PubMed]

101. Iliev, I.D.; Leonardi, I. Fungal dysbiosis: Immunity and interactions at mucosal barriers. Nat. Rev. Immunol. 2017, 17, 635-646. [CrossRef]

102. Qiu, X.; Zhang, F.; Yang, X.; Wu, N.; Jiang, W.; Li, X.; Li, X.; Liu, Y. Changes in the composition of intestinal fungi and their role in mice with dextran sulfate sodium-induced colitis. Sci. Rep. 2015, 5, 10416. [CrossRef]

103. Khatib, R.; Riederer, K.M.; Ramanathan, J. Faecal fungal flora in healthy volunteers and inpatients. Mycoses 2001, 44, 151-156. [CrossRef] [PubMed]

104. Agirbasli, H.; Ozcan, S.A.; Gedikoglu, G. Fecal fungal flora of pedi-atric healthy volunteers and immunosuppressed patients. Mycopathologia 2005, 159, 515-520. [CrossRef]

105. Gosiewski, T.; Salamon, D.; Szopa, M.; Sroka, A.; Malecki, M.T.; Bulanda, M. Quantitative evaluation of fungi of the genus Candida in the feces of adult patients with type 1 and 2 diabetes-A pilot study. Gut Pathog. 2004, 6, 43-47. [CrossRef] [PubMed]

106. Chen, Y.; Chen, Z.; Guo, R.; Chen, N.; Lu, H.; Huang, S.; Wang, J.; Li, L. Correlation between gastrointestinal fungiand varying degrees of chronic hepatitis B virus infection. Diagn. Microbiol. Infect. Dis. 2011, 70, 492-494. [CrossRef]

107. Martin Relloso, M.J.; Sanchez-Fayos, P.; Gonzalez, G.A. Colonic histo-plasmosis in AIDS. Endoscopy 2005, 37, 1036. [CrossRef]

108. Patel, N.M.; Schwartz, D.J. Lower GI bleeding from ileocolonic histoplasmo-sis. Gastrointest. Endosc. 2011, 74, 1404-1405. [CrossRef]

109. Gutierrez, D.; Weinstock, A.; Antharam, V.C.; Gu, H.; Jasbim, P.; Shi, X.; Dirks, B.; Krajmalnik-Brown, R.; Maldonado, J.; Guinan, J.; et al. Antibiotic-induced gut metabolome and microbiome alterations increase the susceptibility to Candida albicans colonization in the gastrointestinal tract. FEMS Microbiol. Ecol. 2020, 96, 87. [CrossRef] [PubMed]

110. Guinan, J.; Thangamani, S. Antibiotic-induced alterations in taurocholic acid levels promote gastrointestinal colonization of Candida albicans. FEMS Microbiol. Lett. 2018, 365, 18. [CrossRef]

111. Monasky, R.; Villa, S.; Thangamani, S. An Ex vivo Assay to Study Candida albicans Hyphal Morphogenesis in the Gastrointestinal Tract. J. Vis. Exp. 2020, 1, 161. [CrossRef]

112. Guinan, J.; Villa, P.; Thangamani, S. Secondary bile acids inhibit Candida albicans growth and morphogenesis. Pathog. Dis. 2018, 76, 3. [CrossRef] [PubMed]

113. Guinan, J.; Wang, S.; Hazbun, T.R.; Yadav, H.; Thangamani, S. Antibiotic-induced decreases in the levels of microbial-derived short-chain fatty acids correlate with increased gastrointestinal colonization of Candida albicans. Sci. Rep. 2019, 9, 8872. [CrossRef]

114. Guo, R.; Zheng, N.; Lu, H.; Yin, H.; Yao, J.; Chen, Y. Increased diversity of fungal flora in the vagina of patients with recurrent vaginal candidiasis and allergic rhinitis. Microb. Ecol. 2012, 64, 918-927. [CrossRef]

115. Anderson, M.R. Evaluation of vaginal complaints. J. Am. Med. Assoc. 2004, 291, 1368-1379. [CrossRef] [PubMed]

116. Marrazzo, J.M. Interpreting the epidemiology and natural history of bacterial vaginosis. Clin. Microbiol. 2011, 17, 186-190.

117. Gibbs, R.S. Asymptomatic bacterial vaginosis: Is it time to treat? Am. J. Obstet. 2007, 196, 495-496. [CrossRef] [PubMed] 
118. Fuochi, V.; Li Volti, G.; Furneri, P.M. Lactobacilli dominance and vaginal pH: Why is the human vaginal mirobiome unique? Front. Microbiol. 2017, 8, 19-36. [CrossRef] [PubMed]

119. Förster, T.M.; Mogavero, S.; Dräger, A.; Graf, K.; Polke, M.; Jacobsen, I.D.; Hube, B. Enemies and brothers in arms: Candida albicans and gram-positive bacteria. Cell. Microbiol. 2016, 18, 1709-1715. [CrossRef]

120. Kaewsrichan, J.; Peeyananjarassri, K.; Kongprasertkit, J. Selection and identification of anaerobic lactobacilli producing inhibitory compounds against vaginal pathogens. FEMS Immunol. Med. Microbiol. 2006, 48, 75-83. [CrossRef] [PubMed]

121. Okkers, D.J.; Dicks, L.M.T.; Silvester, M.; Joubert, J.J.; Odendaal, H.J. Characterization of pentocin TV35b, a bacteriocin-like peptide isolated from Lactobacillus pentosus with a fungistatic effect on Candida albicans. J. Appl. Microbiol. 1999, 87, 726-734. [CrossRef]

122. Niu, X.X.; Li, T.; Zhang, X.; Wang, S.X.; Liu, Z.H. Lactobacillus crispatus modulates vaginal epithelial cell innate response to Candida albicans. Chin. Med. J. 2017, 130, 273. [CrossRef] [PubMed]

123. Lourenço, A.; Pedro, N.A.; Salazar, S.B.; Mira, N.P. Effect of Acetic Acid and Lactic Acid at Low pH in Growth and Azole Resistance of Candida albicans and Candida glabrata. Front. Microbiol. 2019, 9, 3265. [CrossRef]

124. Boris, S.; Barbés, C. Role played by Lactobacilli in controlling the populationof vaginal pathogens. Microbes Infect. 2000, 2, 543-546. [CrossRef]

125. De Oliveira, F.E.; Rossoni, R.D.; de Barros, P.P.; Begnini, B.E.; Junqueira, J.C.; Jorge, A.O.C.; Leão, M.V.P.; de Oliveira, L.D. Immunomodulatory effects and anti-Candida activity of lactobacilli in macrophages and in invertebrate model of Galleria mellonella. Microb. Pathog. 2017, 110, 603-611. [CrossRef]

126. Cools, P.; Jespers, V.; Hardy, L.; Crucitti, T.; Delany-Moretlwe, S.; Mwaura, M.; Ndayisaba, G.F.; van de Wijgert, J.H.H.M.; Vaneechoutte, M. A multi-country cross-sectional study of vaginal carriage of Group B Streptococci (GBS) and Escherichia coli in resource-poor settings: Prevalences and risk factors. PLoS ONE 2016, 11, e0148052. [CrossRef]

127. Kho, Z.Y.; Lal, S.K. The Human Gut Microbiome-A Potential Controller of Wellness and Disease. Front. Microbiol. 2018, 9, 1835. [CrossRef]

128. Plaza-Diaz, J.; Ruiz-Ojeda, F.J.; Gil-Campos, M.; Gil, A. Mechanisms of Action of Probiotics. Adv. Nutr. 2019, 10, S49-S66. [CrossRef] [PubMed]

129. Rossoni, R.D.; de Barros, P.P.; Mendonça, I.D.C.; Medina, R.P.; Silva, D.H.S.; Fuchs, B.B.; Junqueira, J.C.; Mylonakis, E. The Postbiotic Activity of Lactobacillus paracasei 28.4 Against Candida auris. Front. Cell Infect. Microbiol. 2020, 10, 397. [CrossRef] [PubMed]

130. Mundula, T.; Ricci, F.; Barbetta, B.; Baccini, M.; Amedei, A. Effect of Probiotics on Oral Candidiasis: A Systematic Review and Meta-Analysis. Nutrients 2019, 10, 2449. [CrossRef] [PubMed]

131. Leonardi, I.; Paramsothy, S.; Doron, I.; Colombel, J.F.; Semon, A.; Kaakoush, N.O.; Clemente, J.C.; Faith, J.J.; Borody, T.J.; Mitchell, H.M.; et al. Fungal Trans-kingdom Dynamics Linked to Responsiveness to Fecal Microbiota Transplantation (FMT) Therapy in Ulcerative Colitis. Cell Host Microbe 2020, 27, 823-829. [CrossRef]

132. Matsuo, K.; Haku, A.; Bi, B.; Takahashi, H.; Kamada, N.; Yaguchi, T.; Saijo, S.; Yoneyama, M.; Goto, Y. Fecal Microbiota Transplantation Prevents Candida Albicans from Colonizing the Gastrointestinal Tract. Microbiol. Immunol. 2019, 63, 155-163. [CrossRef] 